\title{
Comunicação
}

[Communication]

\section{Sorotipos de Streptococcus suis identificados em suínos com meningite no estado do Paraná}

[Streptococcus suis serotypes identified from meningitis cases in pigs in Parana, Brazil]

\author{
D.L. Rocha, L.F. Santos ${ }^{*}$, D.L. Santos, W.M.T. Costa, J.L. Santos
}

Microvet - Microbiologia Veterinária Ltda, Viçosa-MG

O Streptococcus suis é uma bactéria de distribuição mundial, frequente na população de animais, tais como suínos, equinos, cães, gatos, caprinos, ovinos e pássaros (Higgins e Gottschalk, 2006). É um importante agente infeccioso, especialmente de suínos, podendo causar meningite, septicemia, polisserosite, endocardite, artrite e morte súbita (Higgins e Gottschalk, 2006; Del'Arco et al., 2008).

São descritos 35 sorotipos de $S$. suis, sendo que os sorotipos entre 1 e 9 são os mais frequentes associados a doenças em suínos (Higgins e Gottschalk, 2006). A identificação dos sorotipos de $S$. suis responsáveis pelo quadro clínico em cada granja é fundamental para a adoção de medidas profiláticas. Autores têm sugerido o uso de vacinas específicas para os sorotipos identificados (Salgado, 2003), em razão da diversidade genética e da diferença na virulência entre amostras de $S$. suis, mesmo em amostras de um mesmo sorotipo (Higgins e Gottschalk, 2006; Fittipaldi et al., 2009).

Apesar da importância do S. suis como causador de doenças em suínos, poucos estudos foram encontrados no Brasil sobre a frequência de sorotipos de S. suis envolvidos em casos de meningites (Pagnani et al., 2002; Del'Arco et al., 2008).

Os objetivos deste estudo foram determinar os principais sorotipos de $S$. suis envolvidos em casos de meningites em suínos na região dos Campos Gerais, no Paraná, e discutir aspectos relevantes referentes à epidemiologia desse agente na produção de suínos nessa região.

O estudo analisou 76 amostras de S. suis oriundos de suínos doentes, com idade entre 20 e 150 dias, provenientes de granjas tecnificadas localizadas na região dos Campos Gerais no estado do Paraná. As amostras foram isoladas no laboratório Microvet ${ }^{\circledR}$, entre setembro de 2005 e setembro de 2009. Nesse período, foram analisadas amostras de 30 granjas de suínos com plantel reprodutivo entre 200 a 3000 matrizes, totalizando 16000 matrizes. O material coletado durante a necrópsia foi devidamente acondicionado na caixa isotérmica e no gelo, sendo o tempo de transporte até o laboratório de 36 horas. O critério para inclusão das amostras de $S$. suis no estudo foi o isolamento dessas amostras do sistema nervoso central de suínos com sinais clínicos nervosos, tais como decúbito lateral, ataxia, sialorreia e opistótono.

As amostras de $S$. suis foram obtidas como parte do procedimento de rotina do setor de diagnóstico do laboratório Microvet ${ }^{\circledR}$. Após abertura da calota craniana, realizada no laboratório, foram coletados suabes de cérebro e meninges. Os suabes foram suspendidos em $2 \mathrm{~mL}$ de salina tamponada (PBS), $\mathrm{pH} 7,2$, inoculados em ágar sangue de carneiro a $5 \%$ e incubados em aerobiose a $37^{\circ} \mathrm{C}$ por 24 a 48 horas. As colônias suspeitas detectadas foram submetidas à coloração de Gram e a testes bioquímicos, em especial testes para catalase e amilase, crescimento em meio com 6,5\% de $\mathrm{NaCl}$ e o teste de Voges-Proskauer (Amass et al., 1997;

Recebido em 27 de setembro de 2011

Aceito em 12 de janeiro de 2012

*Autor para correspondência (corresponding author)

E-mail: lucasvet2003@globo.com 
Luque et al., 1998). As amostras confirmadas de $S$. suis foram sorotipadas por meio de coaglutinação utilizando soro hiperimune de coelho para os sorotipos entre 1 e 9 e $1 / 2$ (Gottschalk et al., 1993; Del'Arco et al., 2008).

O S. suis sorotipo 2 foi o mais frequente $(73,7 \%)$, seguido pelos sorotipos $1(6,6 \%), 1 / 2(5,3 \%), 3$
$(3,9 \%), \quad 6(3,9 \%), 5(2,6 \%)$, não sorotipado $(2,6 \%)$ e $7(1,3 \%)$, detectados no sistema nervoso central de suínos doentes. Em 20 (66,7\%) granjas, apenas um sorotipo de $S$. suis foi identificado no sistema nervoso central de suínos doentes, enquanto em $10(33,3 \%)$ granjas foram identificados entre dois e cinco sorotipos (Tab. $1)$.

Tabela 1. Número de sorotipos de S. suis isolados do sistema nervoso central de suínos doentes, por granja

\begin{tabular}{lcc}
\hline Quantidade de sorotipos & Número de granjas & Percentual de granjas (\%) \\
\hline Um sorotipo & 20 & 66,7 \\
Dois sorotipos & 5 & 16,7 \\
Três sorotipos & 4 & 13,3 \\
Quatro sorotipos & 0 & 0,0 \\
Cinco sorotipos & 1 & 3,3 \\
\hline Total & 30 & 100,0 \\
\hline
\end{tabular}

Este é o primeiro estudo de frequência de sorotipos de $S$. suis detectados de suínos com meningite na região dos Campos Gerais. O estado do Paraná está entre os maiores produtores e exportadores de carne suína do Brasil, sendo Campos Gerais uma das mais importantes regiões suinícolas do estado (Abipecs, 2008). Estes resultados também refletem o desenvolvimento da produção de suínos na região com o serviço de diagnóstico atuante e a busca por medidas efetivas de controle profilático.

Estes resultados são, em parte, similares a outros estudos realizados no Brasil, em que os sorotipos 2, 3 e 7 (Pagnini et al., 2002) e os sorotipos 2, 1 e 3 (Del'Arco et al., 2008) foram os mais frequentes. Nos Estados Unidos, Fittipaldi et al. (2009) relataram os sorotipos 3, 2 e 7 como os mais frequentes em suínos com infecção por $S$. suis, enquanto na Europa os sorotipos 2 e 9 estão entre os mais frequentes (Higgins e Gottschalk, 2006; Kock et al., 2009; Wei et al., 2009). Esta similaridade entre os sorotipos de $S$. suis em suínos doentes no Brasil com amostras de $S$. suis de linhagens americanas e europeias é esperada, uma vez que importantes linhagens de reprodutores utilizadas no Brasil provêm desses países. Segundo Higgins e Gottschalk (2006), a transmissão entre rebanhos ocorre usualmente pela introdução de animais saudáveis portadores. O sorotipo 9, não identificado no presente estudo, foi relatado no Brasil por Del'Arco et al. (2008) em 0,3\% das 323 amostras de S. suis detectadas.

A diversidade de sorotipos de $S$. suis identificados no sistema nervoso central de suínos doentes demonstrou a importância do apoio laboratorial para estabelecer o diagnóstico preciso. Esta diversidade de sorotipos de S. suis relacionada à infecção em suínos também foi descrita por Fittipaldi et al. (2009), em que 16 sorotipos foram encontrados. A identificação dos agentes bacterianos, bem como dos sorotipos, envolvidos é fundamental para a elaboração de vacinas autógenas eficazes.

A prevenção das doenças por $S$. suis em suínos por meio de vacinas pode ser uma importante oportunidade para a redução no uso de antibióticos na produção de suínos. Essa redução na utilização de drogas tem sido uma constante exigência do mercado consumidor em todo o mundo. Além disso, autores de diferentes áreas da medicina relataram as vacinas como o melhor método, inclusive considerando-se a relação custo-benefício, para o controle e a prevenção de doenças infecciosas (Friendship e Prescott, 2006; Farhat et al., 2008; Paul Pierre, 2009).

Palavras-chave: suínos, Campos Gerais, vacinas, diversidade 


\begin{abstract}
A total of 76 samples of Streptococcus suis isolated from meningitis cases in pigs from 2005 to 2009 were evaluated. The samples were collected from 3 to 21 -week-old pigs raised in 30 farms located in Paraná state, Brazil. The samples of S. suis were obtained as part of routine procedures and were serotyped by coagglutination test using rabbit hyperimmune sera for the serotypes 1 to 9 and $1 / 2$. S. suis type 2 was the most frequent, followed by serotypes $1,1 / 2$ and 3 .
\end{abstract}

Keywords: pig, Streptococcus suis, serotypes, Paraná

\section{REFERENCIAS}

ABIPCES. Relatórios: Carne Suína Brasileira em 2008. Brasília: Associação Brasileira da Indústria Produtora e Exportadora de Carne Suína, 2008. Disponível em: http://www.abipecs.com.br Acessado em: 01 dez. 2009.

AMASS, S.F.; SANMIGUEL, P.; CLARK, L.K. Demonstration of vertical transmission of Streptococcus suis in Swine by genomic fingerprinting. J. Clin. Microbiol., v.35, p.15951596, 1997.

DEL'ARCO, A.E.; SANTOS, J.L.; BEVILACQUA, P.D. et al. Swine infection by Streptococcus suis: a retrospective study. Arq. Bras. Med. Vet. Zootec., v.60, p.878-883, 2008.

FARHAT, C.L.; WECKX, L.Y.; CARVALHO, L.H.F.; SUCCI, R.C.M. Imunizações: Fundamentos e Prática. São Paulo: Atheneu, 2008. 566 p.

FITTIPALDI, N.; FULLER, T.E.; TEEL, J.F. et al. Serotype distribution and production of muramidase-released protein, extracellular factor and suilysin by field strains of Streptococcus suis isolated in the United States. Vet. Microbiol., v.139, p.310-317, 2009.

FRIENDSHIP, R.M.; PRESCOTT, J.F. Drug Therapy and Prophylaxis. In: STRAW, B.; ZIMMERMAN, J.; ALLAIRE, S.; TAYLOR, D. (Eds.). Diseases of Swine. 9.ed. Ames, Iowa: Iowa State Univ., 2006. p.1131-1143.

GOTTSHALK, M.; HIGGINS, R.; BOUDREAU, M. Use of polyvalent reagents for serotyping of Streptococcus suis. J. Clin. Microbiol., v.32, p.2192-2194, 1993.
HIGGINS, R.; GOTTSCHALK, M. Streptococcal diseases. In: STRAW, B.; ZIMMERMAN, J.; D'ALLAIRE, S.; TAYLOR, D. (Eds.). Diseases of Swine. Ames: Iowa State Univ., 2006. p.769783.

KOCK, C.; BEINEKE, A.; SEITZ, M. et al. Intranasal immunization with a live Streptococcus suis isogenic of mutant elicited suilysin-neutralization titers but failed to induce opsonizing antibodies and protection. Vet. Immunol. Immunopathol., v.132, p.135-145, 2009

LUQUE, I.; TARRADAS, C.; ARENAS, A. et al. Streptococcus suis serotypes associated with different disease conditions in pigs. Vet. Rec., v.27, p.726-727, 1998

PAGNANI, K.J.R.; CASTRO, A.F.P.; GOTTSCHALK, M. et al. Sorotipagem de amostras de Streptococcus suis isoladas de suínos em granjas dos estados de São Paulo, Minas Gerais e Paraná. Pesq. Vet. Bras., v.22, p.1-5, 2002.

PAUL-PIERRE, P. Emerging diseases, zoonoses and vaccines to control them. Vaccine, v.27, p.6435-6438, 2009.

SALGADO, C.J.L. Produção e avaliação de bacterina autógena contra meningite estreptocóccica em suínos. 2003. 68f. Dissertação (Mestrado em Medicina Veterinária) - Escola de Veterinária, Universidade Federal de Viçosa, Viçosa.

WEI, Z.; LI, R.; ZHANG, A. et al. Characterization of Streptococcus suis isolates from the diseased pigs in China between 2003 and 2007. Vet. Microbiol., v.137, p.196-201, 2009. 